\title{
Managing self congruity to influence behavioral intention in organic food contexts in Fujian province, China
}

\author{
Tsai-Fa Yen* \\ Anxi College of Tea Science, Fujian Agriculture and Forestry University, Fujian, China; No.15 Shangxiadian Rd., Cangshan District, \\ Fuzhou City, Fujian, 350002, China (P.R. China)
}

\begin{abstract}
Regarding China, this country is considered as one of the most potential markets in terms of economic growth and population expansion in organic food. Due to the improvement in living standards such as increase in income and healthy consciousness, Chinese consumers start to focus more on food quality, and hence create the chance for the development of organic food market. How to attract consumers' attention has become an emergency issue for both academia and practioners. This study was aims at investigating the effects of gender on self congruity- behavioral intention relationships. Questionnaire survey was employed for collecting data and 200 valid samples were received from those consumers in Fujian province, China. Findings show that self congruity has significantly positive impacts on behavioral intention. However the effects of gender on self congruity- behavioral intention relationships were not significant. Firms should hold more family reunions of organic food in order to enhance its image and maintain the interaction and linkage among consumers.
\end{abstract}

\section{Introduction}

Organic food has developed impressively, from a neglected niche market to the food market mainstream [1]. More and more researchers and practitioners are attracted and involved. As Marian, Chrysochou, Krystallis, and Thogersen [2] ascertained from several studies, the attitude of consumers towards organic food is in general positive with typically associated benefits being superior taste, more environmental-friendliness, improved health, safer food, and more animal welfare. The demand towards organic food is growing dynamically in China. China organic food market is estimated to cross RMB 2.48 billion in 2015 and its production will have a growth rate of an average of $20 \%$ to $20 \%$ in the future ten years [3]. Understanding the attitude and intentions of consumers towards organic food in China will benefit the academia and practitioners.

The foci of prior research into organic foods consumption included identifying motivations behind their purchase to understand the "whys" of consumers' choices. The key drivers previously identified include health benefits and environmental concerns (e.g., $[4,5,6])$, assafety concerns regarding conventional foods (e.g., [4]), as well psychological motives [7].

However, despite the valuable insights provided by previous studies, at least two research gaps exist, which must be addressed. That is, previous studies have neglected psychological motives (i.e., self-congruity) and an important role of organic foods, gender. In particular, initial psychological motives, such as selfcongruity, deserve attention given their impact on consumers' product choices. Consumers purchase goods/services because they are driven by a motivation to express their own self-images $[8,9,10]$. Thus, a product or brand that defines, sustains, and enhances the self-images of consumers is more likely to be selected and purchased [11]. This possibility that psychological motives can play an important role in organic product consumption has not been researched in this context.

Second, gender difference is an important variable in the marketing literature $[12,13,14]$. However, the studies on gender differences in the context of organic foods, as well as its influence on formation of intention, have rarely been carried out. Thus, examination of the role of gender in intention formation contributes to the existing organic foods literature. More importantly, gender could be an easy recognized variable for marketers. Rather than other demographic characteristics (e.g., family income, or level of education), gender is can be quickly judged by consumers' appearance in most situations [15]. Therefore, accurate marketing strategies could be done to provide a better service, which may further increase the level of consumers' intention and purchase behaviors.

Therefore,this study examines the role of a psychological motive(i.e.,self-congruity) and gender that havebeenidentified inpreviousorganicfoodstudies or marketing literature. The current research demonstrates the relative importance of this variable in stimulating consumers' consumption of organic foods. To our knowledge, this is the first study to clarify the importance of self-congruity in predicting consumers' intention to purchase organic foods. Therefore, the results enrich our understanding of key drivers of consumers' organic food purchase.

A core proposition is that the effects of selfcongruity on purchase intention depend on the magnitude of gender in the organicfood context. Selfcongruity should play a lesser role when genderismale and a greater role when genderisfemale. This proposition, if supported would (1) augment existing psychological motive(i.e.,self-congruity)- purchase intention models

Corresponding author: 1722997311@qq.com 
which focus mostly on self-congruity; (2) help to explain variability in the self-congruity- purchase intention relationshipevidenced in prior research; and (3) provide guidance to organicfoodindustry in developing selfcongruity- purchase intention programs.

\section{Methodology}

\subsection{Population}

Having considered the data collection requirements of this study such as a need of large sample of organic food consumers in Fujian province, it would be appropriate to employ the field survey with a self- administered questionnaire as the primary data collection technique. The population was set on those organic food consumers who consume organic food during the past six month. Organic firms were conducted for collecting data. After giving them phone call/interview by the researcher, finally four organic firms agreed to give us help in collecting data. They were found more than 5 years, stood on a standard of operation, and could be the representation of organic food firms in Fujian province. Their main products of those firms were fresh organic vegetables, organic tea, and others.

\subsection{Instrument}

The field study method was chosen in order to gain information directly from organic food consumers who consume organic food during the past six month. As such, their perceptions about the setting with respect to self-congruity (SC) and behavioral intention (BI) are likely to be clearly in mind.

The survey instruments were borrowed from previous studies and adapted for this study. Selfcongruity was defined as how a consumer hopes others see her/him. A consumer's self-image congruity comprises their actual self-congruity, ideal self-congruity, social self-congruity, and ideal social self-congruity [16]. Four items for self-image congruity are distinguished, based on the studies of Ryu \& Lee (2013) [17] and Yen (2013) [18]. Behavioral intention was defined as a consumer's evaluation of the intents to word-of-mouth, recommendation, and repurchase [19].Three items for behavioral intentions are drawn from Lee \& Yun (2015) [19] and Yen (2013) [13].

\subsection{Survey}

Quota sampling was adopted for collecting data based upon firms scale. Regarding to the feasibility and accessibility, four firms were adopted for collecting data after conducting to legal organic firms in Fujian province. They have offered the member list for sending questionnaires or space for surveyors to interview the organic food consumers. Survey was down during May to June in 2016. Finally a total of 218 samples were received. After non-qualified and incomplete surveys were excluded, the remaining 200 respondents were valid reporting a responds rate of valid samples was $91.7 \%$.

Of 200 questionnaires obtained, about $45.5 \%$ were male and $55.5 \%$ were from female respondents. At about $16.5 \%$ of respondents were below 22 years of age, $20.5 \%$ of respondents were 22-32 years of age, $20 \%$ of respondents were $32-42$ years of age, $28 \%$ of respondents were $42-52$ years of age, and 9\% exceed52 years of age. Regarding to married status, $38.5 \%$ of respondents was single while $56 \%$ of respondents were married with children. Approximately $8 \%$ of respondents were graduated from junior high school and 19\% of respondents were graduated from senior high school. At about $72.5 \%$ respondents were graduated from college or above. With regard to the occupation, $16 \%$ of respondents work at government related section, 7.5\% of respondents belong to industrial section, $14 \%$ of respondents were businessman, $10.5 \%$ of respondents were farmers, and $34.5 \%$ of respondents were retired. Approximately $20 \%$ of respondent's monthly income was below $3000 \mathrm{RMB}, 43.5 \%$ of respondent's monthly income was $3000-6000 \mathrm{RMB}, 22.5 \%$ of respondent's monthly income was $6000-8000 \mathrm{RMB}$, and $8.5 \%$ of respondent's monthly income exceeds 8000 RMB. With regard to the frequency consumed within six month, $27 \%$ of respondents were less than three times, $31 \%$ of respondents were 4-6 times, and $39.5 \%$ of respondents were more than seven times.

\section{Result}

\subsection{Descriptive statistics}

Normality was tested by means of SPSS 17.0, based on the skewness and kurtosis of the observed variables [20]. Both samples revealed acceptable kurtosis (-0.838 $\sim-0.384)$ and skewness $(-0.223 \sim-0.028)$ for most observed variables (see Table 1$)$.

\subsection{Analysis for measurement model}

Data analysis was conducted using structural equation modeling with AMOS 19.0. According to the guidelines offered by Anderson and Gerbing (1988) [21], a confirmatory factor analysis (CFA) was performed and then a structural model was estimated. During the process of CFA, several items were excluded from the model due to low standardized factor loadings, low squared multiple correlations, and high standardized residuals. The final CFA results (see Table 2) indicated that the fit indices showed a satisfactory fit to the data: $\chi^{2}=20.95, \mathrm{df}=13(\mathrm{p}=.074), \chi^{2} / \mathrm{df}=1.61, \mathrm{GFI}=.972$, AGFI $=.939, \quad \mathrm{CFI}=.987, \mathrm{RMSEA}=.055$. Means, standard deviations, and Cronbach's $\alpha$ among the constructs are presented in Table 1.

\subsection{Convergent validity}

As shown in Table 2, all estimated factor loadings in the measurement model showed high factor loading 
coefficients and significant t-values (all loadings ranging from 0.66 to $0.919, \mathrm{p}<0.001$ ). The results of composite reliability and the average variance extracted (AVE) value of each multi-item scale showed that high reliabilities were achieved for all scales with values ranging from .791 to .864; the AVE was between .486 and .683 . Therefore, convergent validity was met.

Table 1. Descriptive statistics.

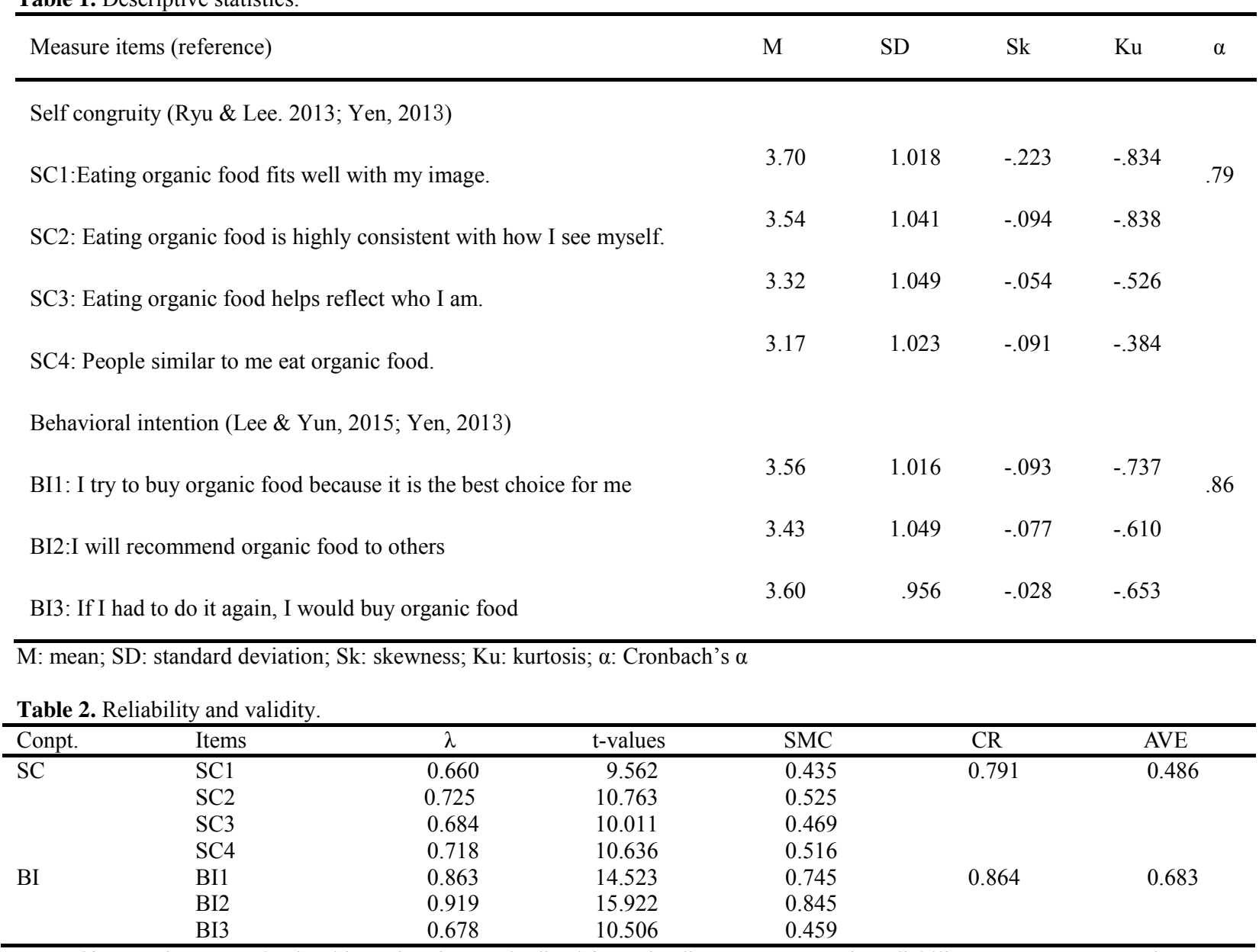

SC: Self congruity; BI: Behavioral intention; $\lambda$ : Standardized factor loading; CR: Composite reliability; AVE: Average variance extracted; $\chi^{2}=20.95, \mathrm{df}=13(\mathrm{p}=0.074), \chi^{2} / \mathrm{df}=1.61, \mathrm{GFI}=0.972, \mathrm{AGFI}=0.939, \mathrm{CFI}=0.987, \mathrm{RMSEA}=0.055$

\subsection{Discriminant validity}

To examine the discriminant validity (i.e., the distinctiveness of constructs) for all constructs, the AVEs related to each latent construct were compared to the squared correlations between the corresponding constructs. The evidence of discriminant validity exists when AVE from each construct exceeds the squared correlations [22]. The AVEs ( 0.486 for SC and 0.683 for $\mathrm{BI})$ by the underlying construct should be larger than the shared variance (i.e., the squared correlation coefficient) between two constructs (0.396). Based on the tests, therefore, all constructs were considered to be distinctively different, confirming discriminate validity.

\subsection{Analysis for structural model}

The next step was the structural model test of the causal relationships between constructs in the proposed model.
The results revealed a good level of fit for the structural model: $\quad \chi^{2}=20.95, \quad \mathrm{df}=13(\mathrm{p}=0.074), \quad \chi^{2} / \mathrm{df}=1.61$, GFI $=0.972$, AGFI $=0.939$, CFI $=0.987$, RMSEA $=0.055$. Based on these fit measures, it can be concluded that the model is acceptable. The standardized parameter estimates, t-values, and fit indices are reported in Table 3. Next, the individual parameters/paths in the structural path model were evaluated. Specifically, the hypotheses were tested by evaluating the relationships between the exogenous and endogenous variables. Table 3 reports the findings of the main effects, and it was found that self congruity was significantly and positively related to behavioral intention $(\beta=0.628)$, supporting $\mathrm{H} 1$.

\subsection{The moderating effects of gender on SC-BI relationship}

Next, the moderating effects of gender were assessed using the multi-group analysis in the SEM framework. The full sample was divided into male $(n=65)$ and 
female ( $n=135$ ) sub-groups. First, the theoretical model, which contains both groups, was examined without constraining any parameters (i.e., the unconstrained model or base model). The next step was to estimate a "fully constrained" structural path model in which all regression path coefficients were constrained to be equal across both groups. Comparing the goodness-of-fit statistics for the constrained model and unconstrained model using a $\chi^{2}$ difference test, in which a $\Delta \chi^{2}$ value can be used to examine whether a particular path coefficient estimation is statistically different across the male and female groups. The $\Delta \chi^{2}$ values for constrained model is not significantly increased $\left(\Delta \chi^{2}=2.65, \Delta \mathrm{df}=10\right.$, $\mathrm{p}>0.05$ ), which means the two-group analysis is not theoretically supported. Therefore, the H2 is not supported.

Table 3. Results of SEM.

\begin{tabular}{|c|c|c|c|}
\hline Path and items & $\beta$ & $\mathrm{t}$ & $\mathrm{SMC}$ \\
\hline SC-BI & 0.628 & 6.696 & 0.395 \\
\hline $\mathrm{SC} 1$ & 0.660 & 9.562 & 0.435 \\
\hline $\mathrm{SC} 2$ & 0.725 & 10.763 & 0.525 \\
\hline $\mathrm{SC} 3$ & 0.684 & 10.011 & 0.469 \\
\hline $\mathrm{SC} 4$ & 0.718 & 10.636 & 0.516 \\
\hline BI1 & 0.863 & 12.758 & 0.745 \\
\hline $\mathrm{BI} 2$ & 0.919 & 13.292 & 0.845 \\
\hline $\mathrm{BI} 3$ & 0.678 & 9.758 & 0.459 \\
\hline
\end{tabular}

Table 4. the comparison among gender.

\begin{tabular}{lrrr}
\hline \multicolumn{1}{c}{ Paths and items } & \multicolumn{1}{c}{ All $(\mathrm{n}=200)$} & Male $(\mathrm{n}=65)$ & \multicolumn{1}{c}{ Female $(\mathrm{n}=135)$} \\
\cline { 2 - 4 } & \multicolumn{1}{c}{$\beta$ (t-values $)$} & $\beta$ (t-values $)$ & $\beta(\mathrm{t}$-values $)$ \\
\hline SC-BI & $0.628(6.736)$ & $0.837(3.975)$ & $0.543(6.736)$ \\
SC1:Eating organic food fits well with my image. & $0.660(9.562)$ & $0.733(6.445)$ & $0.622(9.562)$ \\
SC2: Eating organic food is highly consistent with & $0.725(10.763)$ & $0.735(6.467)$ & $0.738(10.763)$ \\
how I see myself. & $0.684(10.011)$ & $0.743(6.560)$ & $0.664(10.011)$ \\
SC3: Eating organic food helps reflect who I am. & $0.718(10.636)$ & $0.771(6.907)$ & $0.677(10.636)$ \\
SC4: People similar to me eat organic food. & $0.863(12.758)$ & $0.814(5.130)$ & $0.878(12.758)$ \\
BI1: I try to buy organic food because it is the best & $0.919(13.292)$ & $0.889(5.265)$ & $0.915(13.292)$ \\
choice for me & $0.678(9.758)$ & $0.736(4.788)$ & $0.646(9.758)$ \\
BI2:I will recommend organic food to others & 0.395 & 0.700 & 0.295 \\
BI3: If I had to do it again, I would buy organic food & 20.95 & 62.403 & 15.680 \\
$\mathrm{R}^{2}$ & $13(\mathrm{p}=0.074)$ & $13(\mathrm{p}=0.000)$ & $13(\mathrm{p}=0.267)$ \\
$\chi^{2}$ & 1.61 & 4.8 & 1.206 \\
df & 0.972 & 0.809 & 0.968 \\
$\chi^{2} / \mathrm{df}$ & 0.939 & 0.588 & 0.930 \\
GFI & 0.987 & 0.815 & 0.993 \\
AGFI & 0.055 & 0.244 & 0.039 \\
CFI & &
\end{tabular}

\section{Conclusion}

The main purpose of this study was to propose and examine a theoretical model of behavioral intention formation and to address the differences between males and females in terms of how they form behavioral intention toward organic food, using data obtained from
Moreover, this study compares the path coefficient estimation between genders. Table 4 reports that the effects of self congruity on behavioral intention within the relationship between genders, the path coefficient estimation was larger in male than in female. The largest indicator of self congruity for male respondents was "People similar to me eat organic food", however it's "Eating organic food is highly consistent with how I see myself" for female respondents. Within the four types of self-concept as well as self congruity, the preference between genders could be met. Male respondents preferred ideal social self-concept but female respondents preferred social self-concept. In summary, ideal self-concept was fond to be the most important one in influencing behavioral intention and followed by ideal social self-concept, social self-concept and actual selfconcept when purchasing organic food. This finding was different from previous studies. 
behavioral intention; and the influence of self congruity on behavioral intention was stronger for males.

In terms of theoretical implications, this study contributed to the body of knowledge on self congruityand behavioral intention in organic food context in two major ways. First, a theoretical model of behavioral intention formation is presented and empirically examined with a relatively large sample of real organic food consumers in Fujian province, China.This study empirically examined howself congruity influence behavioral intention. That is, within the four type of self image, the order of its importance/components can be found. According to Sirgy (1982) [16], self-concept is a multidimensional construct having four major components, namely, actual self-concept, ideal self-concept, social self-concept and ideal social self-concept. Ideal self-concept was fond to be the most important one in influencing behavioral intention and followed by ideal social self-concept, social self-concept and actual self-concept when purchasing organic food.

Moreover, the study demonstrated that the influence of self congruityonbehavioral intention was stronger for males than for females but it's not significant indicating that male and female consumer form different behavioral intentiontoward the organic food depending on different self congruity components. For males, ideal social selfconcept was the key component, but ideal self-concept would be important for females when predicting behavioral intentiontoward the organic food.

Finally, the marketers of organic food need to pay more emphasize on ideal conceptand ideal social concept of organic food. This would enhance consumers'ideal self-concept and ideal social self-concept and thus bridge the gap between organic food image and consumers' self image. Consequently they will have positive image/words of mouth on organic food, will recommendorganic food to others, and most importantly they will buy it again and again. With regard to future research, they can extend the model to other countries and collect more samples to improve the litmiation of the sample size used in the study.

\section{References}

1. J. Van Doorn, P.C.Verhoef, Drivers and barriers to organic purchase behavior, J. Retailing, 91(3), 436-450 (2015)

2. L. Marian, P. Chrysochou, A. Krystallis, J. Thogersen, The role of price as a product attribute in the organic food context: An exploration based on actual purchase data, Food Quality and Preference, 37, 52-60 (2014)

3. MOA, 2015, Ministry of Agriculture, People's of Republic of China, http://www.moa.gov.cn/

4. N. Michaelidou, L.M. Hassan, The role of health consciousness, food safety concern and ethical identity on attitudes and intentions towards organic food, Int. J. Consumer Study, 32(2), 163-170 (2008)

5. E. Tsakiridou, C. Boutsouki, Y. Zotos, K. Mattas, Attitudes and behaviour towards organic products: an exploratory study, Int. J. Retailing Distribution Management, 36 (2), 158-175 (2008)

6. M. Wandel, A. Bugge, Environmental concern in consumer evaluation of food quality, Food Quality and Preference, 8(1), 19-26 (1997)

7. C. C. Teng, C. H. Lu, Organic food consumption in Taiwan: Motives, involvement, and purchase intention under the moderating role of uncertainty, Appetite, 105, 95-105 (2016)

8. D. Aaker, Building Strong Brands. Free Press, New York. (1996)

9. F. Kressmann, M. Sirgy, A. Herrmann, F. Huber, S. Huber, D. Lee, Direct and indirect effects of self-image congruence on brand loyalty, J. Business Research, 59, 955-964(2006)

10. P.H. Chiou, T.F. Yen, K.K. Chu, Tourists' behavioral intentions in rural area: An integrated aspect of SCT and TPB, J. Food, Agriculture \& Environment, 13(3\&4), 168-174 (2015)

11. T. Graeff, Using promotional messages to manage the effects of brand and self-image on brand evaluations, J. Consumer Marketing, 13 (3), 4-18 (1996)

12. C. Wang, H. Qu, M. K. Hsu, Toward an integrated model of tourist expectation formation and gender difference, Tourism Management, 54, 58-71(2017)

13. J. Hwang, H. Han, W. Kim, Organic food as selfpresentation: The role of psychological motivation in older consumers' purchase intention of organic food, $J$. Retailing and Consumer Services, 28, 281-287 (2016)

14. Y. King, P. Wan, Minding the gap in the gaming industry, Int.J. Contemporary Hospitality Management, 26 (1), 130-153 (2014)

15. H. Han, B. Meng, W. Kim, Bike-traveling as a growing phenomenon: Role of attributes, value, satisfaction, desire, and gender in developing loyalty, Tourism Management, 59, 91-103 (2017)

16. M. J. Sirgy, Self-concept in consumer behavior: a critical review, J. Consumer Research, 9, 287-300 (1982) 17. K. Ryu, J. S. Lee, Understanding convention attendee behavior from the perspective of self-congruity: The case of academic association convention, Int. J. Hospitality Management, 33, 29-40 (2013)

18. T.F. Yen, Understanding Tourists' Intention from self-image congruity: An empirical study from B\&B in Kenting, Leisure Industry Research, 11(3), 1-14 (2013) 19. H.J. Lee, Z.S. Yun, Consumers' perceptions of organic food attributes and cognitive and affective attitudes as determinants of their purchase intentions toward organic food, Food Quality and Preference, 39, 259-267(2015)

20. K. A. Bollen, Structural equations with latent variables, New York: John Wiley \& Sons. (1989)

21. J.C. Anderson, D.W. Gerbing, Structural equation modeling in practice: a review and recommended twostep approach, Psychological Bulletin, 103(3), 411-423 (1988)

22. C. Fornell, D. Larcker, Evaluating structural equation models with unobservable variables and measurement error, J. Marketing Research, 18(1), 39-50 (1981) 